\title{
Biological vs. Chemical Treatments of Agrowastes: Chemical, Physical and Morphological properties
}

\author{
Roushdy M. M. ${ }^{\text {; }}$ Mahdy M. Hesham ${ }^{1}$; Houssni El Saied ${ }^{2}$; Altaf H. Basta and \\ M. S. Hassanin ${ }^{2}$ \\ 1- Botany and Microbiology Department, Faculty of Science, Al-Azhar University, Nasr \\ City, Cairo 11884, Egypt \\ 2- Cellulose and Paper Department, National Research Centre, Dokki, Cairo 12622, \\ Egypt \\ E-mail: m27roushdy@yahoo.com
}

\begin{abstract}
i) Aims

The purpose of this study is to improve the surface structure of rice husks, using solid state fermentation (SSF), as eco- treatment process compared to conventional chemical treatments (alkali, and acidic treatments).
\end{abstract}

\section{ii) Main Methods}

A mixed culture of Aspergillus awamori and Cunninghamella elegans in SSF was a proper organisms isolated and used in this investigated treatment. All media used for solid state fermentation were prepared by substituted the carbon source in the foregoing media by RHs fibers, and the incubation period 7 days at $30^{\circ} \mathrm{C}$. The beneficial effect of investigated treatment was evaluated by comparing the chemical constituents, IR measurements, thermal stability using non-isothermal thermogravimetric technique, and surface imaging using scanning electron microscope of the treated fibers, with that produced from conventional chemical treated fibers.

\section{iii) Key Findings}

The results showed that the investigated biological treatment had positive effect for removing the hemicelluloses and lignin, with preserving the strength of fibers, compared to chemical treated RH. The FTIR- and TGA- measurements, as well as SEM, evident this view.

These results suggest a promising hope that offers the possibility of producing valuable cellulosic material from Egyptian agro-wastes that eventually will be highly amenable for several industries that may improve the Egyptian economy.

\section{iv) Significance}

The studies performed should assist future efforts toward applying new biological treatment for RHs fibers, for further application. In addition, application of the extreme processing conditions to traditional one could prove interesting.

Keywords: Rice husks, chemical treatment, Biological treatment, eco-treatment, FTIR, Non-isothermal TGA.

\section{INTRODUCTION}

Egypt is the largest rice producer in the Near East region, where rice cultivation area occupies over 1,080,000 Acre with an average farm yield of 4.76 tons/Acre and an approximate straw production of 2.4 tons/Acre (Sabaa and Sharaf 2000). Currently, the major practice to eliminate such massive amounts of post-harvest rice residues is field open air burning. Although field burning provides effective destruction of weed seeds and pathogenic microbial spores, the produced black smoke represents a threat to public health. 
The burning results in respiratory particles of less than $10 \mathrm{~mm}$ in diameter, which are a major cause of respiratory ailments such as asthma emphysema; it also introduces carbon monoxide and some nitrogen dioxide, which has statistically significant effect on asthma morbidity (Schwartz et al. 1993). About the utilization of plant wastes, many physico-chemical and biological methods were studied, such as incineration technology and aerobic microbial decomposition (Strayer et al., 1997; Wignarajah et al. 2000).

Cellulose fibers are a raw material with excellent physical properties (high specific stiffness and tensile strength) but the surface offers very little chemical reactivity. Most of the hydroxyl groups (both primary and secondary) on the cellulose fiber form tight interactions in the crystal lattice and are therefore slow to undergo chemical reactions. A very selective and mild reaction is needed to modify the available surface hydroxyl groups without disrupting the crystal lattice and altering the physical properties of the fiber. Extensively substituted cellulose derivates e.g. cellulose acetate, are widely used in applications that do not rely on the load-bearing properties of microfibrils. Several authors have demonstrated a mild oxidation process for polymeric carbohydrates such as potatostarch, inulin, guar-gum, pullulan, dextrines, cellulose and chitosan (Bragd et al. 2000; Bragd et al. 2001; Bragd et al. 2002; Lenzi et al. 2003).

Many studies are currently focused on altering the properties of cellulosebased fibres via chemical or physical modification for further applications. This study reports one approach to compare these chemical and physical modifications with biological modification using microorganisms that target cellulose as a carbon source and subsequently improving its structure and composition. Biological treatment of cellulosic fibers involves the use of whole organisms or their enzymes in pretreatment of lignocellulosic fiber. Both fungi and bacteria are used for biotreatment of lignocellulosic material. Commercial preparations of fungal and bacterial hydrolytic and oxidative enzymes are also widely used instead of these microorganisms. Fungal pretreatment of agricultural residues is a recent method for improvement of lignocellulosic material compatibility (Sinegani et al., 2005). In addition, there are also a number of ancillary enzymes that attack hemicellulose, such as xylanases enzymes (Roman et al., 2006). Ligninolytic enzymes are primarily involved in lignin degradation in oxidative reactions that are mainly free radical driven in the presence (or sometimes absence) of mediators. The main enzymes involved are lignin peroxidase, manganese peroxidase and laccase (Mtui and Masalu, 2008). Removal of non-cellulosic compounds would also expose the hydroxyl groups on the fibre (Daniel and Volc, 2004). White, brown, and soft-rot fungi were used to degrade lignin and hemicellulose in waste materials whereby brown rots mainly attacked cellulose; while white and soft rots attacked both cellulose and lignin. White-rot fungi were the most effective for biological pretreatment of lignocellulosic materials (Sun and Cheng, 2002).

Two authors of this article also reported that, deashing and dewaxed the rice straw, by conventional chemical and biological treatments had a significant effect on performance of the produced active carbon (Basta et al., 2011a and $\mathrm{Li}$ et al., 2011) as well as RS is efficient agro-fibers for production cemented fiber-boards and particle-boards (Basta et al., 2011b and 2014).

The purpose of this study is to improve the surface structure of rice husks. This was carried out through new biological treatment (solid state fermentation; SSF), in comparison to 
conventional chemical treatments (alkali, and acidic treatments), as a trial to enhance the improvement of surfaces of cellulose-based agro-wastes. Finally, the investigated SSF method and conventional chemical treatment were compared according to their results for determination of the most effective one.

\section{Experimental :}

\section{Natural fibers preparation}

The RHs collected from Egyptian rice mills were used as the fibers for the natural fiber lignocellulosic materials. RHs milled and subsequently subjected for washing and drying overnight at $50^{\circ} \mathrm{C}$. Dried rice husks successively subjected to several stages of grinding and sieving to different fraction sizes and the rice byproducts of 20-40 mesh fractions were selected for chemical and physical analyses.

\section{Treatment of RHs fibers Chemical modification}

Two chemical procedures were involved including alkali and acidic treatments. For alkali treatment, the RHs were treated by different concentrations of Sodium hydroxide, namely: 3, and $12 \%$ (based on oven dry weight), at liquor ratio $1: 7$, and $50^{\circ} \mathrm{C}$ for $1 \mathrm{hr}$. Then it was subjected for washing by tap water followed by acetic acid $10 \%$, and washed by tap water again till the neutralization occurs.

For acidic treatment, RHs were treated with two concentrations of sulfuric acid, namely: 0.5 , and $1.0 \% \mathrm{v} / \mathrm{v}$, at liquor ratio 1:9. This acid hydrolysis was carried out in autoclave at $110^{\circ} \mathrm{C}$ for $1 \mathrm{hr}$. The produced fibers were washed by tap water till neutralization occurs then subjected to drying in air, followed by oven at temperature of $100^{\circ} \mathrm{C}$. At the end of the process the resulted RHs fibers were subjected for further chemical and physical analysis.

\section{Biological modification Microbial isolation media}

All isolation media were prepared according to Atlas (2005). Different bacterial and fungal isolates were selected and purified after growing on the collected rice Husks. The bacterial isolates were allowed to grow on nutrient agar media, MacConkey agar media and Czapek-Dox's agar media. Media were autoclaved, inoculated with different RHs fibers and incubated at $28-30^{\circ} \mathrm{C}$. The selection of the grown organisms was dependent on choice of the most potent organism(s) capable of attacking RHs fibers and subsequently altering the composition of cellulose-based fibers through the production of one or a series of hydrolytic enzymes.

\section{Identification of most potent isolates}

The most potent isolates which give the highest mechanical properties were identified at the Culture Collection and Identification Unit of the Regional Center for Mycology and Biotechnology, AlAzhar University. Identification procedure was based on current universal keys as described by Domsch et al. (1993) and Samson et al. (2000).

\section{Solid state fermentation media}

All media used for solid state fermentation were prepared by substituted the carbon source in the foregoing media by RHs fibers containing the following ingredients $(\mathrm{g} / \mathrm{l})$ : RHs fibers, 1000; $\mathrm{NaNO}_{3}, 3.0 ; \mathrm{KH}_{2} \mathrm{PO}_{4}$, $1.0 ; \mathrm{MgSO}_{4} .7 \mathrm{H}_{2} \mathrm{O}, 0.5 ; \mathrm{KCl}, 0.5$; and $\mathrm{FeSO}_{4} .7 \mathrm{H}_{2} \mathrm{O}, 1.0$ in addition of distilled water $1000 \mathrm{ml}$. After inoculation with the most potent organisms and at the end of incubation period (7 days at $30^{\circ} \mathrm{C}$ ), samples of the fermented fibers were collected and assayed for the presence of microbial enzymes.

\section{Cellulase assay}

Cellulase assay was carried out according to reducing sugar estimation using dinitrosalicylic acid (DNS) method (Ghose 1987). Cellulase activity is expressed as the number of umoles of reducing sugars produced per minute of hydrolysis of ml of enzyme used. 
Xylanase (hemicellulase) assay

Xylanase assay was carried out according to Ghose and Bisaria (1987). Xylanase activity is expressed as the number of umoles of reducing sugars produced per minute of hydrolysis of $\mathrm{ml}$ of enzyme used.

\section{Peroxidase Assay}

Bergmeyer (1974) method was used for peroxidase assay. One unit of enzyme activity was defined as the amount of the enzyme that catalyzed the conversion one micromole of $\mathrm{H}_{2} \mathrm{O}_{2}$ per minute at $25^{\circ} \mathrm{C}$.

\section{Chemical analysis of un- and treated RHs fibers}

The chemical analysis procedure was done to estimate the main components of biologically and chemically treated $\mathrm{RHs}$ as well as untreated ones. This included estimation of the following components. The components included resin, wax, lignin, ash (according to TAPPI standard method) and pentosans estimation (method of Jayme and Sarten, 1940)

\section{Physical analysis of RHs fibers}

The physical analysis experiment included the estimation of moisture content as well as the water retention value (Jayme, 1958) of the treated (by biological and chemical treatment) and untreated RHs.

\section{FTIR spectra analysis}

Infrared spectra were carried out using JASCO FTIR at the central Laboratory of National Research Center, Dokki, Egypt, using $\mathrm{KBr}$ disc. The technique of O'Connor et al. 1958 was used to calculate the crystallinity index (Cr.I). The mean strength of hydrogen bonds (MHBS) was calculated according to Levdik et al. 1967.

\section{Thermogravimeteric analysis (TGA)}

Thermogravimetric analysis was performed by a Perkin-Elmer Thermal Analysis Controller AC7/ DX TGA7, using a heating rate of $10^{\circ} \mathrm{C} \mathrm{min}^{-1}$ in nitrogen atmosphere at the center Laboratory of National Research Center. The samples were heated in pure nitrogen (flow rate $50 \mathrm{~mL} / \mathrm{min}$ ) at $10^{\circ} \mathrm{C} /$ minute, and within the typical temperature range: $35-550^{\circ} \mathrm{C}$, i.e., till no additional weight loss was observed. Measurements were made using calcined alumina as reference material. Differential thermogravimetric (DTG) peaks were examined for evidencing different behaviours between the samples, and also for understanding how the pre-treatments affected the thermal stability of fibers produced The kinetic parameters based on the weight loss data of TG curve analysis were determined according to the equations described elsewhere (Coat and Redfern, 1964, Basta 1998) as follow:

\section{TG-curve analysis}

Kinetic studies, based on the weight loss data, were obtained by TG curve analysis. The activation energy has been evaluated by applying Coat and Redfern method of analysis (Coat and Redfern, 1964). For pseudo homogeneous kinetics, the irreversible rate of conversion of the weight fraction of reactant was expressed by the following equation:

$$
\frac{d \alpha}{d t}=k(1-\alpha)^{n}
$$

Where, $\alpha$ is the fraction of material decomposed at time $\mathrm{t}, \mathrm{k}$ is the specific rate constant and $\mathrm{n}$ is the order of reaction. The temperature dependence of $\mathrm{k}$ is expressed by the Arrhenius equation:

$$
k=A e^{E x / R E R}
$$

Where $\mathrm{A}$ is the frequency factor $\left(\mathrm{s}^{-1}\right)$ and $\mathrm{T}$ is the absolute temperature.

For linear heating rate, a, $\left(\right.$ deg.min. $\left.{ }^{-1}\right)$ :

(3)

$$
a=\frac{d r}{d t}
$$

For calculating the activation energy, Ea, of thermal decomposition when $\mathrm{n}=1$, equation 4 was used.

$$
\log \left[-\log \frac{1-\alpha}{T^{2}}\right]=\log \frac{A R}{\alpha E_{y}}\left[1-\frac{2 R T}{E_{\alpha}}\right]-\frac{E_{\alpha i}}{2.8 . R T}
$$


When $n \neq 1$, equation 5 was used;

$\log \left[\frac{1-(1-\omega)^{2-n}}{T^{2}(1-n)}\right]=\log \frac{A E}{Q E_{a}}\left[1-\frac{2 E T}{E_{a k}}\right]$

Plotting the left-hand-side value of the equation $\left\{\right.$ i.e., $\log \left[1-(1-\alpha)^{1-n} / T^{2}\right.$ (1-n) ]\} against $1 / \mathrm{T}$ using various values of " $n$ " should give a straight line with the most appropriate value of " $n$ " (Basta, 1998). The Least square method was applied for the equation, using values of " $\mathrm{n}$ " ranging from 0.0 to 3.0 in increments of 0.5 . The correlation coefficient (r) and the standard error (SE) were calculated for each value of " $n$ ". The " $n$ " value, which corresponds to the maximum $r$ and minimum SE, is the order of the degradation process. The activation energies and frequency factors were calculated from the slope and intercept, respectively, of the Coat-Redfern equation with the most appropriate value of " $n$ ".

Scanning electron microscopy (SEM)

Scanning electron microscopy (gold coating, Edwards Sputter Coater, UK) was performed using a JEOL 6310 (system running at 5-10 keV at the center Lab., National Research Center.

\section{RESULTS}

\section{Components of RHs fibers}

Table 1: Chemical and physical analysis of RHs fibers after chemical modification

\begin{tabular}{|c|l|l|l|l|l|}
\hline \multirow{2}{*}{ Chemical modification type } & \multicolumn{5}{l}{ Components average value (\%) } \\
\cline { 2 - 6 } & Wax and resin & Ash & Pentosans & Lignin* & WRV \\
\hline Control** & 1.78 & 18.5 & 22.8 & 20.6 & 52.4 \\
\hline NaOH concentration & \multicolumn{5}{|l}{} \\
\hline$-\quad 3 \%$ & 0.87 & 16.80 & 27.39 & 20.30 & 71.0 \\
\hline$-\quad 12 \%$ & 0.95 & 8.97 & 22.40 & 19.5 & 53.0 \\
\hline $\mathrm{H}_{2} \mathrm{SO}_{4}$ concentration & 1.62 & 18.7 & 21.9 & 20.4 & 51.5 \\
\hline$-\quad 0.5 \%$ & 1.80 & 20.1 & 19.4 & 20.1 & 50.3 \\
\hline$-\quad 1.0 \%$ & & & & \\
\hline
\end{tabular}

*Kalson lignin

**Control: RHs fibers without any modification

The results showed a promising hope of using $\mathrm{NaOH}$ in a concentration of
The grinded fibers were analyzed to detect the untreated lignocellulosic fibers (RHs) characterization. Table (1) showing the chemical constituents, physical 2 añlysis, of the natural RHs fibers without either chemical or microbial modification. The chemical analysis showed the main composition (\%) of lignocellulosic fibers, such as wax and resin, ash, pentosans, and lignin; while the physical analysis showed their affinity to absorb water, which was determined from measuring the water retention value (WRV). From the data, it is obvious that there was an increase in pentosans ratio as well as the water retention value. Actually, this result is in agreement with Hosseinaei et al. (2012) who stated that the water retention value may increases by increase in pentosans percentage.

\section{Chemical modification of RHs fibers}

The chemical and physical properties of RHs were studied after treatment of fibers with alkali and acidic substances. Alkali treatment was carried out on the RHs fibers at different sodium hydroxide concentrations (3, and 12\%) based on dry weight of the fibers. Data of the modified fibers were recorded in Table (1). Acidic modification was carried out using two main acid concentrations of sulphuric acid i.e. 0.5 and $1.0 \%(\mathrm{w} / \mathrm{w})$. 
observed with marinating the WRV and pentosans when compared to the control; however $3 \% \mathrm{NaOH}$ provided unacceptable increase in WRV. On the other hand, there was no valuable for purifying the $\mathrm{RH}$ from undesirable silica, wax and lignin, or little effect of acidic modification. Nadazi et al. (2007) had supported these results. They mentioned that soda has a good effect on the surfaces and characters of fibers when compared to acidic modification.

\section{Biological modification of RHs fibers}

Eleven bacterial and fungal isolates (Table 2) were isolated form rice husks and purified for further screening of their abilities to produce cellulases, peroxidases and xylanases.

Table 2: Bacterial and fungal isolates and their enzymatic productivity

\begin{tabular}{|c|c|c|c|}
\hline Microbial isolate Symbol & Xylanase production & Cellulase production & Peroxidase production \\
\hline \multicolumn{4}{|l|}{ Bacterial isolates } \\
\hline B1 (G+ve Cocci) & $\mathrm{UD}^{*}$ & ++ & + \\
\hline B2 (G+ve Bacilli) & + & +++ & UD \\
\hline B3 (G+ve Bacilli) & UD & +++ & + \\
\hline B4 (G-ve Bacilli) & + & ++ & + \\
\hline B5 (G-ve Bacilli) & Trace & + & + \\
\hline B6 (G-ve Bacilli) & + & + & + \\
\hline \multicolumn{4}{|l|}{ Fungal isolates } \\
\hline F1 & ++ & Trace & + \\
\hline $\mathrm{F} 2$ & + & UD & + \\
\hline F3 & + & + & + \\
\hline F4 & +++ & UD & ++ \\
\hline F5 & ++ & UD & +++ \\
\hline
\end{tabular}

$* \mathrm{UD}=$ Undetected

All cellulase producers' six bacterial isolates) were neglected, where they may breakdown the main backbone of the fibers (cellulose) which loosen its properties and make it not suitable to be applied in several industrial applications. On the other hand, hemicelluase and peroxidase producers were selected as desired microorganisms (four fungal isolates) where they breakdown the hemicelluloses backbone which is considered as one of the most undesired component in lignocellulosic fibers; while the other three isolates were neglected.

\section{Identification of the fungal isolates}

Identification of the most potent isolates revealed that they were identified as Aspergillus awamori and Cunninghamella elegans for fungal isolates of symbols $\mathrm{F} 4$ and F5 respectively (Figs. 1A and B).

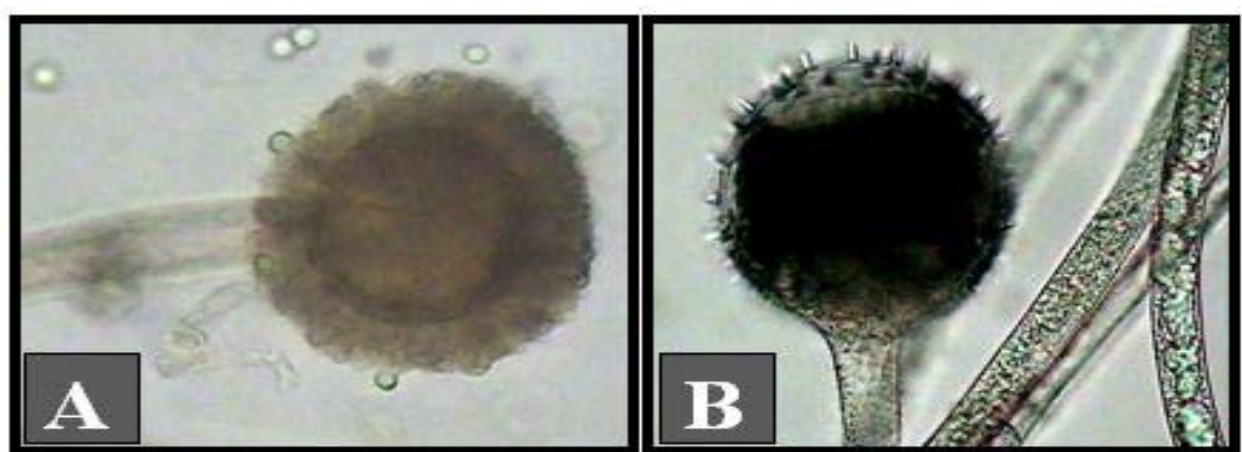

Fig. 1: Fungal image of A- Aspergillus awamori (F4 isolate) and B- Cunninghamella elegans (F5 isolate).

Comparison between chemical and biological modification of RHs fibers
Table 3 showed the comparative analysis between untreated, biologically 
(BT) and chemically treated (CT) fibers through the chemical and physical analysis of their components.

Further analyses were carried out for comparison between the chemical and physical modification of such fibers, to recommend which treatment is more effective, e.g., FT-IR-spectra, nonisothermal thermogravimetric analysis, as well as scanning electron micrograph (SEM). For this purpose different experiments were carried out including the following tests.

Table 3: Chemical and physical properties of biologically and chemically treated RHs.

\begin{tabular}{|l|l|l|l|l|l|}
\hline \multirow{2}{*}{ Type of Modification } & \multicolumn{3}{|l|}{ Chemical analysis (\%) } & Physical analysis (\%) \\
\cline { 2 - 6 } & Wax and resin & Ash & Lignin & Pentosans & WRV \\
\hline Control* & 1.78 & 18.5 & 20.6 & 22.8 & 52.4 \\
\hline Chemical & 0.95 & 8.97 & 19.6 & 22.4 & 53.0 \\
\hline Biological & 1.77 & 19.1 & 16.8 & 17.9 & 51.0 \\
\hline
\end{tabular}

*Control: Untreated RHs

For the case of IR spectra Figure 2 absorbance intensity. It can be shown and Tables 4 \& 5, show that, both chemical and biological treatments (CT) led to red shift the band maxima corresponding to stretching vibration of $\mathrm{OH}$ (from $3416 \mathrm{~cm}^{-1}$ to $3405 \mathrm{~cm}^{-1}$ and $3386 \mathrm{~cm}^{-1}$, for the case of RH-BT \& RHthat, biological treatment provided fibers with relatively higher crystalinity index ( 4.9), than untreated fibers ( 4.2), moreover it led to slightly increased its mean hydrogen bond strength from 1.81 to 1.84 .

$\mathrm{CT}$, respectively), with the increase in its

Table 4: Main IR-absorption bands of un- and treated rice husks.

\begin{tabular}{|l|l|l|l|l|l|l|l|}
\hline Sample & $\begin{array}{l}v_{\mathrm{OH}} \text { or } \\
v_{\mathrm{NH}} \\
\text { tretching) }\end{array}$ & $\begin{array}{c}v_{\mathrm{CH}} \\
\text { (stretching) }\end{array}$ & $\begin{array}{c}v_{\mathrm{C}=\mathrm{O}} \\
\text { (stretching) }\end{array}$ & $\begin{array}{c}v_{\mathrm{OH}} \text { or } v_{\mathrm{NH}} \\
\text { (bending) }\end{array}$ & $\begin{array}{c}v_{-\mathrm{OH}} \\
\text { (phenolic } \\
\text { lignin) }\end{array}$ & $\begin{array}{c}v_{-\mathrm{O}-} \text { (ether } \\
\text { Linkage) }\end{array}$ & $\begin{array}{c}v_{\mathrm{CH}} \\
\text { (rocking) }\end{array}$ \\
\hline RH & 3416 & 2916 & $\begin{array}{l}1694 \\
1615\end{array}$ & 1424 & 1358 & 1196 & 823 \\
\hline RH-CT & 3386 & 2914 & 1623 & 1424 & 1365 & 1143 & 897 \\
\hline RH-BT & 3405 & 2907 & $\begin{array}{l}1696 \\
1629\end{array}$ & 1426 & 1368 & 1159 & 809 \\
\hline
\end{tabular}

Table 5: IR-measurements of un- and treated rice straw

\begin{tabular}{|l|l|l|}
\hline Sample & MHBS & Cr.I \\
\hline Rice husk (RH) & 1.813706 & 4.167442 \\
\hline RH-CT & 1.662814 & 3.186702 \\
\hline RH-BT & 1.835965 & 4.908936 \\
\hline
\end{tabular}



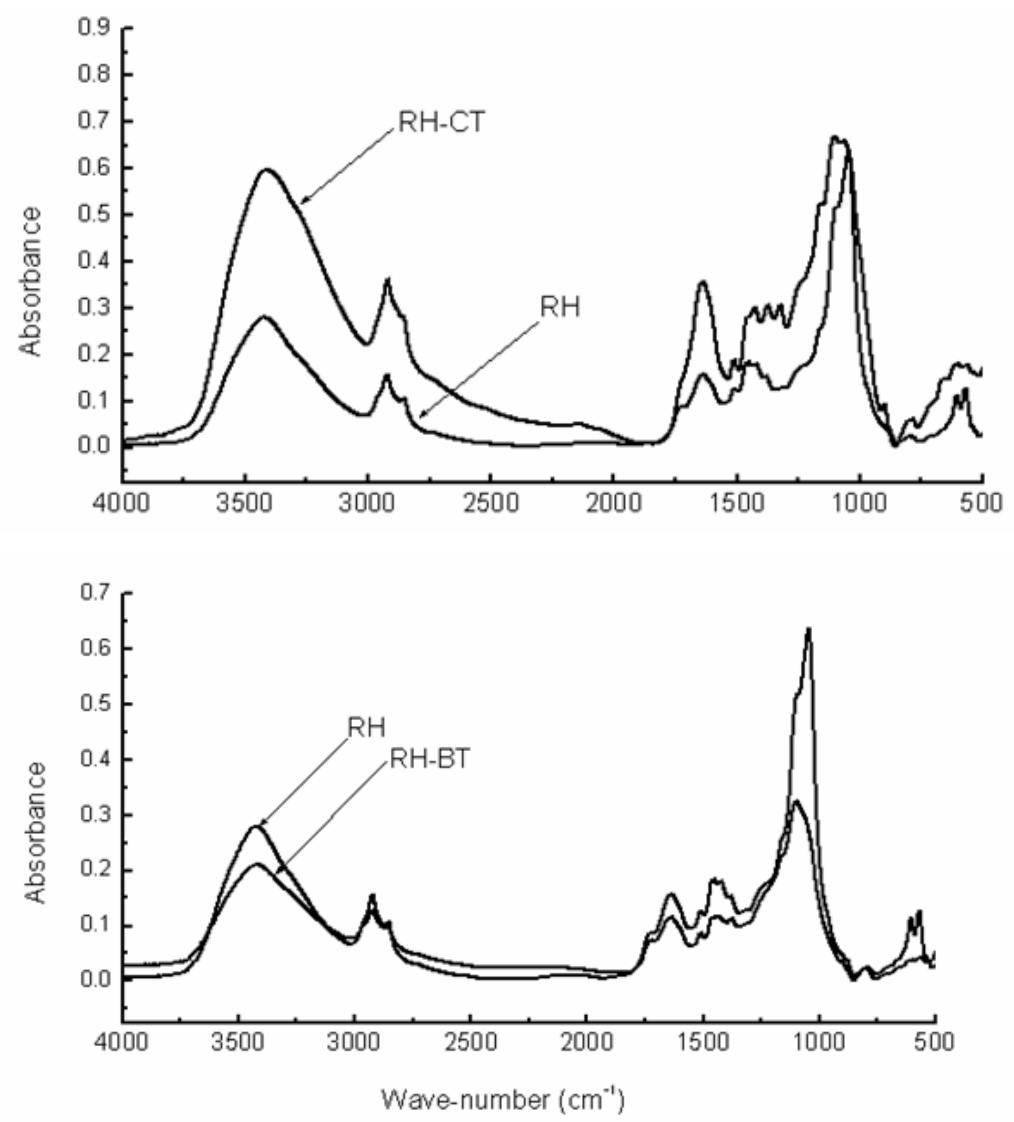

Fig. 2: FT-IR Spectra of untreated and treated RS fibers.

However this trend was reversed in case of chemical treatment (CT), where the CT provided a decrease in crystalinity index and mean hydrogen bond strength from 4.9 to 3.19 and from 1.81 to 1.66 , respectively.

While, for the case of thermogravimertic analysis (TGA), Figure 3 and Table 6 show that, the TGA and DTG curves of untreated RH fibers (Fig. 3, Table 6), show three degradation stages. At lower temperature, i.e. $<144^{\circ} \mathrm{C}$ ( $1^{\text {st }}$ degradation stage), the weight loss is due to the evolution of sorbet moisture. The second process, in the range from $190-332^{\circ} \mathrm{C}$ is due to the decomposition of RS components, leading to the formation of carbonaceous char. This is followed by weight loss within the temperature of $336-479^{\circ} \mathrm{C}$ due to oxidation of charred product. The $2^{\text {nd }}$ and $3^{\text {rd }}$ process regard the main degradation stages.

For the investigated biological treated $\mathrm{RH}(\mathrm{RH}-\mathrm{BT})$ and conventional alkali treated $\mathrm{RH}$ (RH-CT), the start temperature of the $2^{\text {nd }}$ degradation stages is higher than untreated RH (Fig. 3 \& Table 6). As can be noticed that, maximum raise in the start temperature was noticed for investigated RH-BT fibers. Table 6 also shows that, the thermal stability of the foregoing treated samples increase in the order:

$$
\text { RS-BT > RH-CT > RH. }
$$



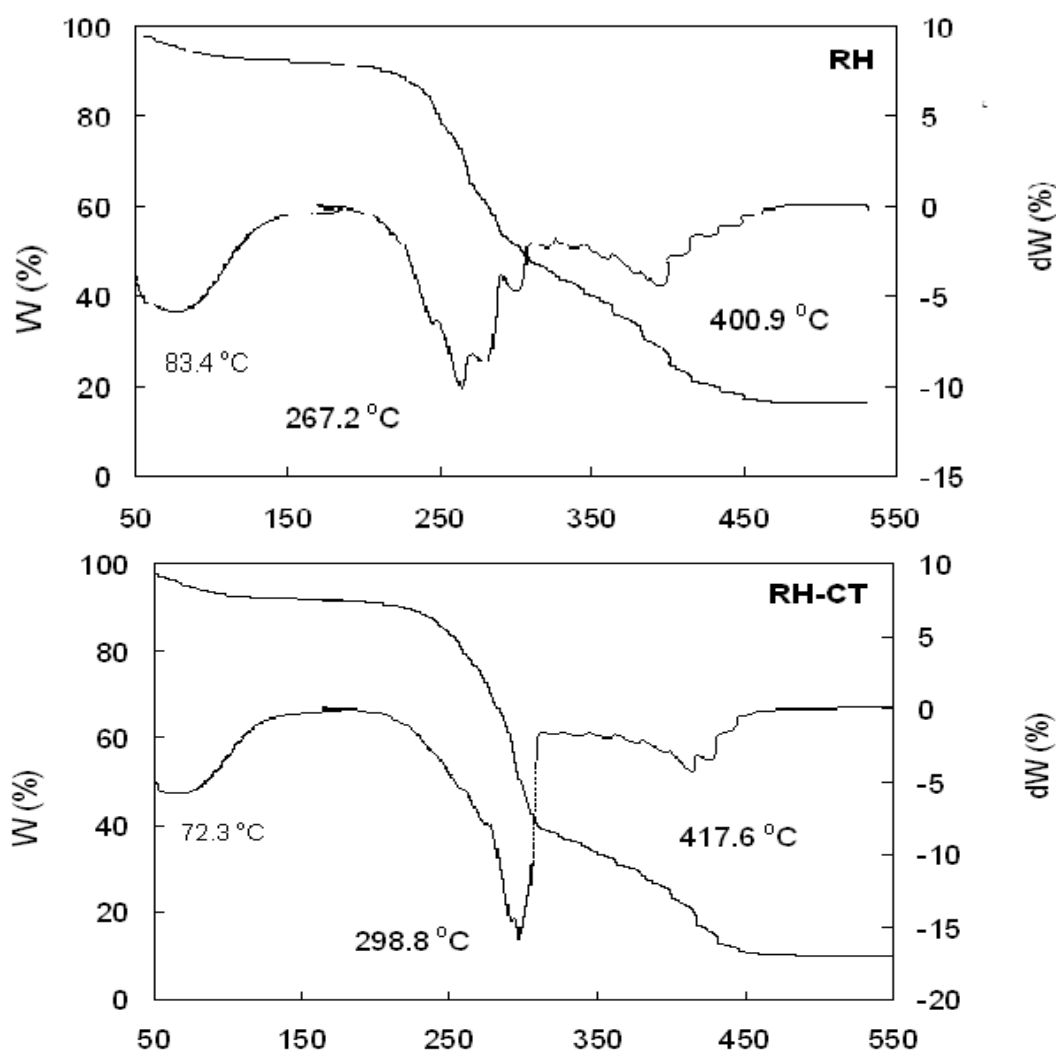

$\sum_{0}^{3}$
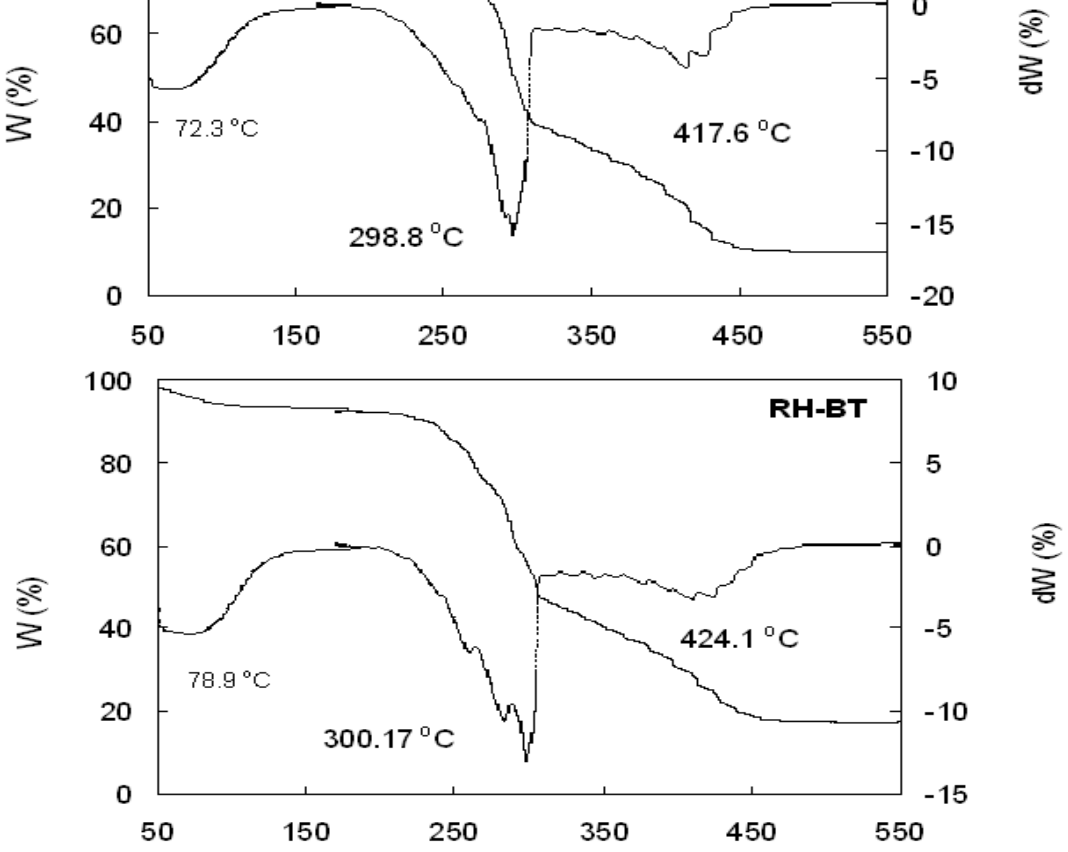

$\sum_{3}^{\varrho}$

Fig. 3: TGA and DTG curves for untreated and treated RH fibers.

Table 6: Kinetic parameters of untreated and treated rice husk

\begin{tabular}{lllllll}
\hline $\begin{array}{l}\text { Sample code } \\
\text { in chart }\end{array}$ & stage & Temp. range ${ }^{\circ} \mathrm{C}$ & $\begin{array}{l}\text { DTG peak } \\
\text { temp, }{ }^{\circ} \mathrm{C}\end{array}$ & "n" & $\mathrm{E}_{\mathrm{a}} \mathrm{kJ} /$ mole & Wt. remain, \% \\
\hline $\mathrm{RH}$ & $1^{\text {st }}$ & $50-144$ & 83 & - & - & 92.4 \\
& $2^{\text {nd }}$ & $190-332$ & 268 & 1.5 & 135.297 & 43.7 \\
& $3^{\text {rd }}$ & $336-479$ & 401 & - & - & 16.6 \\
RH-CT & $1^{\text {st }}$ & $50-134$ & 72 & - & - & 92.1 \\
& $2^{\text {nd }}$ & $197-326$ & 298.8 & 1.5 & 146.2307 & 37.0 \\
RH-BT & $3^{\text {rd }}$ & $332.5-475$ & 417.3 & & - & 10.2 \\
& $1^{\text {st }}$ & $50-134$ & 79 & - & & 93.3 \\
& $2^{\text {nd }}$ & $201-327$ & 300.2 & 1.5 & 154.8839 & 44.3 \\
\hline
\end{tabular}

Where, n: order of degradation reaction,

Ea: Activation energy of degradation. 
Surfaces imaging of RHs using Scanning Electron Microscope (SEM), showed the biological treatment provided good surface treatment for rice husks than chemical treatment by alkali. Where, the surfaces of untreated RH fibers have an irregular phase and fine corrugations which were a highly removed after BT, and provided smoothness surface (Figs. $4 a, b$ and $c)$.

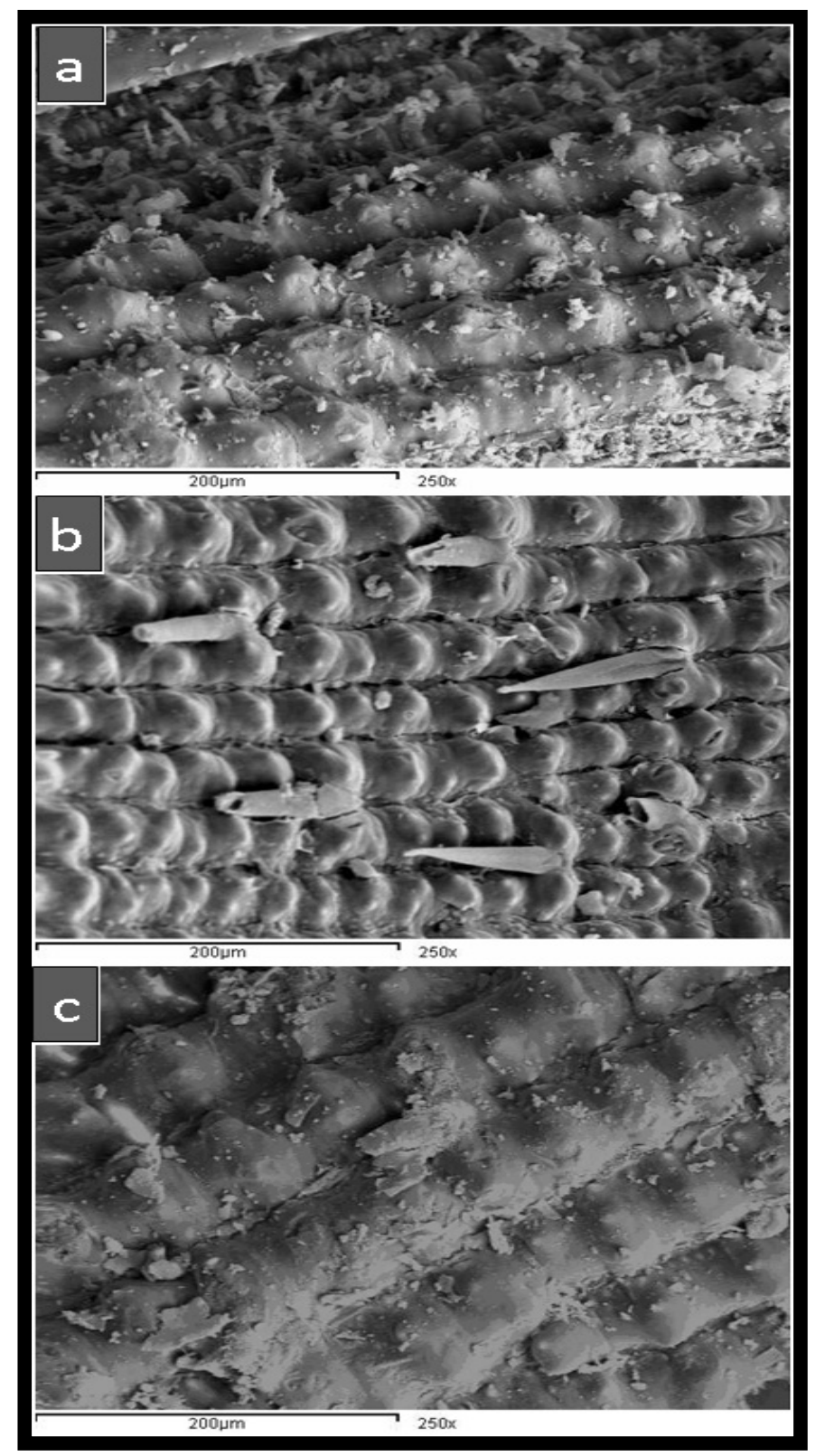

Fig. 4: SEM image of (a) surface of untreated RHs (b) surface of chemically treated RHs, (c) surface of biologically treated RHs

\section{DISCUSSION}

Preliminary evaluating the selected chemical treatment for further applied to treat the $\mathrm{RH}$ fibers in comparison with the investigated surface static fermentation (SSF), the chemical constituents and water retention results registered in Table 2 showed a promising hope of using $\mathrm{NaOH}$ in a concentration of $12 \%$ rather than of $3 \%$. Where, $3 \% \mathrm{NaOH}$ provided RHs fibers with unacceptable increase in WRV (71\%), and lower removing the 
inorganic silica, wax. and pentosans values compared to the untreated RHs. On the other hand, there was no valuable or little effect of acidic modification on purifying the treated fibers from undesirable silica, wax, and lignin. Nadazi et al. (2007) had supported these results. They mentioned that soda has a good effect on the surfaces and characters of fibers when compared to acidic modification.

While the selected the organisms, the eleven bacterial and fungal isolates were tested, using qualitative cellulase xylanase, and peroxidase assays (Table 2). It was cleared that, all cellulase producers (six bacterial isolates) were neglected, where they breakdown, the main backbone of the fibers (cellulose) which loosen its properties and make it not suitable industrial use. On the other hand, hemicelluase and peroxidase producers were selected as desired microorganisms (four fungal isolates) where they breakdown the hemicelluloses backbone which is considered as one of the most undesired component in lignocellulosic fibers. Only two fungal isolates (F4 and F5) were selected as the most potent for the improvement of lignocellulosic fibers properties, while the results of the other three isolates were neglected and this were in agreement with many investigators (Sun and Cheng, 2002 $\mathrm{Li}$ and Pickering, 2009 Hosseinaei et al. 2012).

The beneficial SSF treatment process (BT) than alkali $12 \%$ was evident from chemical and physical analyses (Tables 3-6. and Figures 2-4).

The chemical constituents and WRV (Table 3) revealed that, the BT provided higher purified $\mathrm{RH}$ fibers from non-cellulosic constituents (hemicellulose as pentosans and lignin), compared to CT; while the WRV for both treatments were nearly the same. This observed results is ascribed to Aspergillus awamori and Cunninghamella elegans for fungal isolates, which were used for treated the
$\mathrm{RH}$, manly leads to secret the xylanse and peroxidase. These promising results preserving the environment from disposing liquor, which will resulted from carrying the fiber purification by chemical pulping at higher temperature and/or time.

The changes in structure of treated RHs fibers, in comparison with untreated ones were also estimated from IR-spectra measurements (mean hydrogen bond strength; MHBS, and crystallinity index; CrI.), as well as the position of main functional groups, e.g., hydroxyl and carbonyl groups.

It can be shown that (Figure 2 and Tables 3 \& 4), BT treatments are found to favor the formation of hydrogen bonds and increased the crystallinity index, than CT. As can be noticed the band maxima corresponding to stretching vibration of $\mathrm{OH}$ were red shifted (from $3416 \mathrm{~cm}^{-1}$ to $3405 \mathrm{~cm}^{-1}$ and $3386 \mathrm{~cm}^{-1}$, for the case of RH-BT \& RH-CT, respectively), with the increase in its absorbance intensity. The higher shift in the case of CT is probable ascribed to removal of undesirable components (silica and wax), together with lignin; moreover alkali leads to degradation of cellulose. While the investigated BT leads to remove only hemicellulose and lignin without affect on cellulose chains, therefore it enhances the intra molecular hydrogen bonds between fiber chains. This led to decrease in its WRV than the case of CT.

This means that, the soda chemical treatment mainly improved the composition of lignocellulosic RHs through the elimination of silica and wax; while, BT is mainly purified the $\mathrm{RH}$ fibers from non-cellulosic constituents (hemicellulose and lignin). This view was emphasized from decreasing ether linkage (position around $1160 \mathrm{~cm}^{-1}$ ) with a decreasing in hemicellulose percentage.

The non-isothermal thermogravic analysis (TGA) charts showed the weight loss and its derivatization of untreated and treated $\mathrm{RH}$, as a function of 
temperature (Figure 3). For the investigated biological treated $\mathrm{RHs}(\mathrm{RH}-$ $\mathrm{BT}$ ) and conventional alkali treated $\mathrm{RH}$ (RH-CT), Fig. 3 and Table 6 show that, the start temperature of the $2^{\text {nd }}$ degradation stages is higher than untreated RH. This is due to the removal of low molecular weight hemicellulose (amorphous holocellulose), besides wax and silica, especially for the case of chemical treatment. As can be noticed that, maximum raise in the start temperature was noticed for investigated RH-BT fibers. This is ascribed to the investigated BT provides removing of non-cellulosic compounds with keeping to the silica and wax resin contents (Table 1). As can be possible, BT leads to formation of carboxylic groups, which consequently enhances the formation of intra molecular hydrogen bonding with hydroxyl groups, in other glucopyranose units. The shift of the bands assigned to stretching vibration of $\mathrm{OH}$ to higher frequency of RH-BT than RH-CT, together with increasing its the MHBS than $\mathrm{RH}$ and RH-CT emphasized this view (Tables 4 \& 5). Therefore, more energy is needed for decomposition (Table 6).

The surface change as a result of $\mathrm{Bt}$ and chemical treatments were also examined by SEM photographs (Figure 4). It was showed the highly effective of BT towards providing the smooth surface and removing of irregular phase and fine corrugations, than CT. From the previous evident we can suggest that the biological treatments given the excellent compatible fibers in comparison to chemical treatments. From the previous evident we can suggest that the biological treatments given the excellent compatible fibers in comparison with chemical treatments.

It is concluded that solid-state fermentation is a powerful tool for improving the structure of RHs. In this respect the solid state fermentation process (SSF), was carried out, for production, and selecting the microorganisms, for treated the $\mathrm{RH}$, with self using the rice husks as carbon source of fermentation medium. The SSF investigated treatments were carried out using mixed culture of two strains (Aspergillus awamori and Cunninghamella elegans) isolated from agro-wastes (RHs). The relatively high removing of non-cellulosic components of RHs (hemicellulose as pentosans and lignin), by BT, as well as higher IRmeasurements (mean hydrogen bond strength), TGA-measurements, smoothness SEM micrographs evident the eco-efficient of such treatment than CT.

\section{REFERENCES}

Atlas M. R., (2005). Media for Environmental Microbiology. Hand book, Second edition.

Basta, A.H. (1998). Preparation, characterization and properties of paper sheets made from chemically modified wood pulp treated with metal salts. Int. J. Polym Mat., 42:1-26.

Basta, A.H; Fierro V., El-Saied H. and Celzard, A. (2011a). Effect of deashing rice straws on their derived activated carbons produced by phosphoric acid activation. Biomass and Bioenergy, 35:1954-1959.

Basta, A.H; Sefain M.Z. and El-Reweiny I. (2011b). Role of Some Treatments on Enhancing the Ecofriendly Utilization of Lignocellulosic Wastes in Production of cemented-Fiber Bricks, Bio Resources, 6(2):13591375.

Basta, A.H.; El-Saied, H. and Lotfy, V.F. (2014). Performance assessment of deashed and dewaxed rice straw on improving the quality of RS-based composites. RSC Adv., 4: 21794-21801

Bergmeyer H. O. (1974). Methods of enzymatic analysis.1.Seacondas Acadimic press. New York. 
Bragd, F. L., Besemer, A. C.and van Bekkum, H. (2001). TEMPOderivatives as catalysts in the oxidation of primary alcohol groups in carbohydrates." $\mathrm{J}$. Mol. Catal. a-Chem., 170(1-2):35-42.

Bragd, F. L., Besemer, A. C., van Bekkum, H. (2000). Bromide-free TEMPO mediated oxidation of primary alcohol groups in starch and methyl alpha-Dglucopyranoside.. Carbohydr. Res., 328(3):355-363.

Bragd, F. L., Besemer, A. C., van Bekkum, H. (2002). Selective oxidation of carbohydrates by 4AcNH-TEMPO/peracid systems. Carbohydr. Polym. 49(4):397406.

Coat, A.W. and Redfern, J.P. (1964). Kinetic parameters from thermogravimetric data Nature., 201(4914): 68-69.

Daniel G., and Volc J. (2004). Cryo-FESEM \& TEM immune-techniques reveal new details for understanding white-rot decay of lignocellulose. CR Biol., 327: 861-871.

Domsch, K. H., Games, W., Anderson, T. H. (1993). Compendium of soil fungi. Eching, Germany: IHWVerlag.

Favaro L. Silvia, Lopes S. Milena, Neto A. G. V. de C., De Santana R. R., and Radovanovic E. (2010 b). Chemical, morphological, and mechanical analysis of rice husk/post-consumer polyethylene composites. Composites: Part A., 41: 154-160.

Ghose T. K., (1987). International Union of Pure and applied Chemistry. Pure \& App!. Chem., 59(2):257268.

Ghose T. K., and Bisarla V. S., (1987). Measurement of Hemicelllulase Activities. Pure \& AppI. Chem., 59(12): 1739-1752.
Hosseinaei, O., Wang S., Enayati A. A., and Rials G. T. (2012). Effects of hemicellulose extraction on properties of wood flour and wood-plastic composites. Composites: Part A 43: 686-694.

Jayme, G., Sarten, P. (1940). Strength properties of paper fibers. Naturwiss, 28(52):822-823.

Jayme, G. (1958). Determination and significance of water retention value. Tappi, 41(11):180A-183A.

Lenzi, F., Sannino, A., Borriello, A., Porro, F., Capitani, D., Mensitieri, G. (2003). Probing the degree of crosslinking of a cellulose based superabsorbing hydrogel through traditional and NMR techniques. Polymer, 44(5): 1577-1588.

Levdik, I, Inshakov, M.D; Misyurova, E.P. and Nikitin, V.N. (1967). Study of pulp structure by infrared spectroscopy. Tr. Vses Nauch. Issled. Irst. Tsellyul Bum. Prom., 52:109-111.

Li, X.; Cai, Z..; Winandy, J.; Basta, A.H. (2011). Effect of Oxalic Acid and Steam Pretreatment on the Primary Properties of UF-bonded Rice Straw Particleboards. Ind Crops Prod, 33: 665-669.

Mtui G., and Masalu R. (2008). Extracellular enzymes from Brown-rot fungus Laetioporus sulphureus isolated from mangrove forests of Coastal Tanzania. Sci. Res. Essay, 3:154161.

Ndazi B.S., Karlsson S., Tesha J.V., and Nyahumwa C.W. (2007). Chemical and physical modifications of rice husks for use as composite panels. Composites: Part A., 38: 925-935.

O'Connor, R.T.; Du Pre, E.F., Mitchoum, D. (1958). Applications of infrared absorption spectroscopy to investigations cotton and modified cotton, Pt. I Text Res J., 28: 282290. 
Roman H.J., Burgess J.E., Pletschke B.I. (2006). Enzyme treatment to decrease solids and improve digestion of primary sewage sludge. Afr. J. Biotechnol., 5(10): 963-967.

Sabaa, M. F. Sharaf, M.F. (2000). Egyptian policies for rice development, Cahiers Options Mé diterranéennes, 40:25-36.

Samson, R. A., Hoekstra, E. S. and Frisvad, J.C. (2000). Introduction to food and airborne fungi. Netherlands, Utrecht: Centraalbureau voor Schimmelcultures. p.389.

Schwartz, J., Slater, D., Larson, T. V., Pierson, W. F., Koenig, J. Q. (1993). Particulate air pollution and hospital emergency room visits for asthma in Seattle, Am. Rev. Resp. Dis., 147: 826-831.

Sinegani A.A.S., Emtiazi G., Hajrasuliha S. and Shariatmadari H. (2005).
Biodegradation of some agricultural residues by fungi in agitated submerged cultures. Afr. J. Biotechnol., (10): 1058-1061.

Sun Y., and Cheng J. (2002). Hydrolysis of lignocellulosic materials for ethanol production: A review. Bioresour. Technol., 83(1): 1-11.

Strayer, R. F., Finger, B. W., Alazraiki, M. P., (1997). Evaluation of an anaerobic digestion system for processing CELSS crop residues for resource recovery, Adv Space Res. 20: 2009-2015.

TAPPI Standard Method T222 05-54

Wignarajah, K., Pisharody, S., Fisher, J. W. (2000). Can Incineration technology convert CELSS wastes to resources for crop production? A working hypothesis and some preliminary findings, Adv Space Res., 26:327-333. 